\title{
Measuring the Safety Effect of Raised Bicycle Crossings Using a New Research Methodology
}

\author{
Per GÅRder, Lars Leden, AND URHo PUlKKineN
}

Before-and-after study methodology was developed and applied to evaluating the effect on bicyclists' safety of raising urban bicycle crossings by 4 to $12 \mathrm{~cm}$. In total, 44 junctions were reconstructed in this way in Gothenburg, Sweden. Four of these were studied in detail. Before the implementations, bicyclists were riding either in the roadway or on separate paths parallel to the roadway. The paths then ended with short ramps or curb cuts at each cross street, and bicyclists used nonelevated, marked bicycle crossings, similar to pedestrian crosswalks but delineated by white painted rectangles rather than zebra stripes. The results show that the paths with raised crossings attracted more than 50 percent more bicyclists and that the safety per bicyclist was improved by approximately 20 percent due to the increase in bicycle flow, and with an additional 10 to 50 percent due to the improved layout. However, the increased bicyclist volume means that the total number of bicycle accidents is expected to increase. Besides accident analysis, the change in risk was estimated using four different methods: surveys of bicyclists and experts, respectively; conflict data; and a quantitative expert model. Using a Bayesian approach for combining the results shows that the most likely effect of raising the bicycle crossing is a risk reduction of around 30 percent, compared with the before situation with a conventional bicycle crossing. Motorists and pedestrians also saw safety benefits from this traffic-calming measure.

The city of Gothenburg, Sweden-population around 450,000has since 1992 spent approximately 30 million $\mathrm{SKr}$ (around U.S. $\$ 5$ million) annually on bicycle facilities and specific measures aimed at improving the safety of bicyclists. This has given us a unique opportunity to use before-and-after studies for evaluating the safety effects of different measures. This paper focuses on such a measure: elevating bicycle crossings to a level similar to sidewalks (so-called speed tables) and giving them red pavement to further accentuate them. A typical example of an elevated bicycle crossing is shown in Figure 1. As can be observed, the pedestrian crossing is elevated as well-as a continuous sidewalk across the minor approach. Some of the crossings were raised by as much as $12 \mathrm{~cm}$, having 20-cm-long ramps for crossing automobiles; others were raised by only 4 to $6 \mathrm{~cm}$, having almost vertical, mountable curbs. All the bicycle "paths" run parallel to major streets (typically minor arterials), and the elevated crossings are all across minor streets.

The area studied, consisting of $18.7 \mathrm{~km}$ of sections and 44 intersections (shown in Figure 2), had a total of 126 bicycle accidents reported by police or hospitals in the 5-year period 1988-1992. This large number of accidents initiated the changes in layout. None of the accidents were fatal, but many involved serious injuries. Bicyclevehicle accidents as well as bicycle-pedestrian accidents were much

P. Gårder, Department of Civil and Environmental Engineering, University of Maine, Orono, ME 04469-5711. L. Leden and U. Pulkkinen, Technical Research Centre of Finland, Box 1902, FIN 02044 VTT, Finland. more frequent here than in Gothenburg as a whole, whereas single bicycle accidents accounted for only 47 percent of all bicycle accidents in this area as opposed to 64 percent for the city as a whole. Bicycle-pedestrian accidents accounted for 10 percent here compared with 1 percent of all bicycle accidents citywide. Bicycle-bicycle accidents accounted for 7 percent here as well as citywide.

In 1993, practically all bicycle crossings along these $18.7 \mathrm{~km}$ were elevated. There are 44 intersections in the study area:

- Eklandagatan, between Gibraltargatan and Korsvägen, 5.6 km, 7 intersections;

- Första Långgatan, between Barlastgatan and Järntorget, 2.4 km, 5 intersections;

- Vasagatan, 2.7 km, 12 intersections;

- Linnégatan, 3.8 km, 9 intersections;

- Sprängkullsgatan, 1.5 km, 6 intersections; and

- Övre Husargatan, 2.7 km, 5 intersections.

Along one of the streets, Vasagatan, the intersections were raised already before the reconstruction, but the bicycle path that runs down the middle of the avenue-which used to have gravel surface between the intersections-was now paved with stone-matrix asphalt. A pedestrian path in the center of Vasagatan was also paved and separated from the bicycle path by two lines of paving stones. All but one of the other streets now have dual, one-way bicycle paths along both sides of the roadways. The one exception (Södra vägen has a one-way bicycle path on one side only, resulting in bicyclists in the opposing direction having to ride in the regular travel lane (or use the path and illegally ride in the wrong direction).

Before the implementations, bicyclists were riding either in the roadway or on separate paths parallel to the roadway. The paths then ended with short ramps or curb cuts at each cross street, and bicyclists used nonelevated, marked bicycle crossings, similar to pedestrian crosswalks but delineated by painted white rectangles rather than zebra stripes.

The city of Gothenburg has a database containing police-reported as well as hospital-reported accidents. We were able to extract data from this database for the period January 1988 to September 1996.

Extensive bicycle flow counts were taken at two of the sites and at two control sites, for 2 weeks before reconstruction and for 2 weeks after. Nu-Metrics Countmates were used at the treated sections at one of the control points. Traffic was counted at the other control point with a permanent loop detector sensitive to bicycles. The relationship between bicycle flow and the number of reported accidents in the experimental area was analyzed.

Bicyclists were asked to assess their safety after reconstruction at the treated intersections compared with their safety before. 


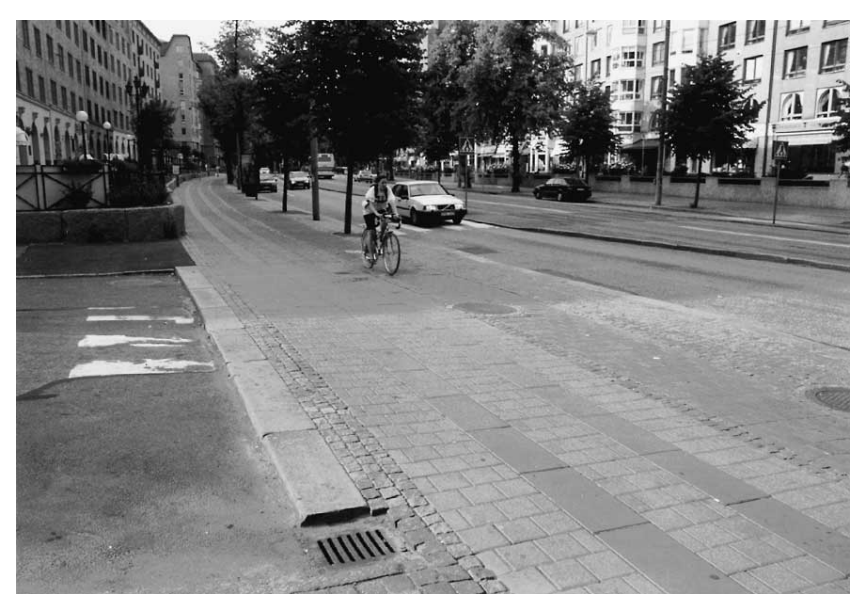

FIGURE 1 Linnégatan-Majorsgatan, Gothenburg, Sweden (after treatment).

An 11-page survey was sent to 22 experts on bicyclists' safety. Planners, as well as researchers, from 13 countries were included. In general, we had no prior knowledge of the answers that could be expected from a certain expert. We received a total of 13 answers: 4 from the Nordic countries ( 2 from Sweden, 1 from Denmark, and 1 from Finland), 4 from other European countries (1 from Austria,
1 from Great Britain, and 2 from the Netherlands), 1 from Canada, 2 from the United States, and 2 from Australia.

The velocity of bicycle traffic, as well as various types of interactions, such as stopping behavior, was studied with the help of video recordings from four junctions before and after reconstruction. Speeds were measured for turning, free-moving motor vehicles at the point of potential conflict with bicyclists. The reason only turning vehicles were included here is that the studied intersections were all T-intersections, so there was no straight-through traffic across the raised bicycle lane. Measured speed data together with the experts' assessments of relations between speed and risk of collision, as well as between speed and injury risk, were input into a quantitative expert judgment model.

The quantitative expert judgment model consists of a risk index model, an expert assessment model, and a risk attribute model. The risk index model defines the measure for risk and describes the dependence of risk on the attributes and parameters of the model. Here, the risk index model is a multiplicative attribute model in which the effect of each attribute on risk may be evaluated separately. The attributes are factors determining the risk. In this case, chosen attributes were the speeds of the vehicles and bicycles. The risk index is not interpreted in a probabilistic way, but it may be viewed as proportional to the accident frequency. The expert assessment model is used for incorporating the assessments made by the experts into the quantitative risk evaluation. We then adopt additive or multiplicative error models (1). Depending on the case, other

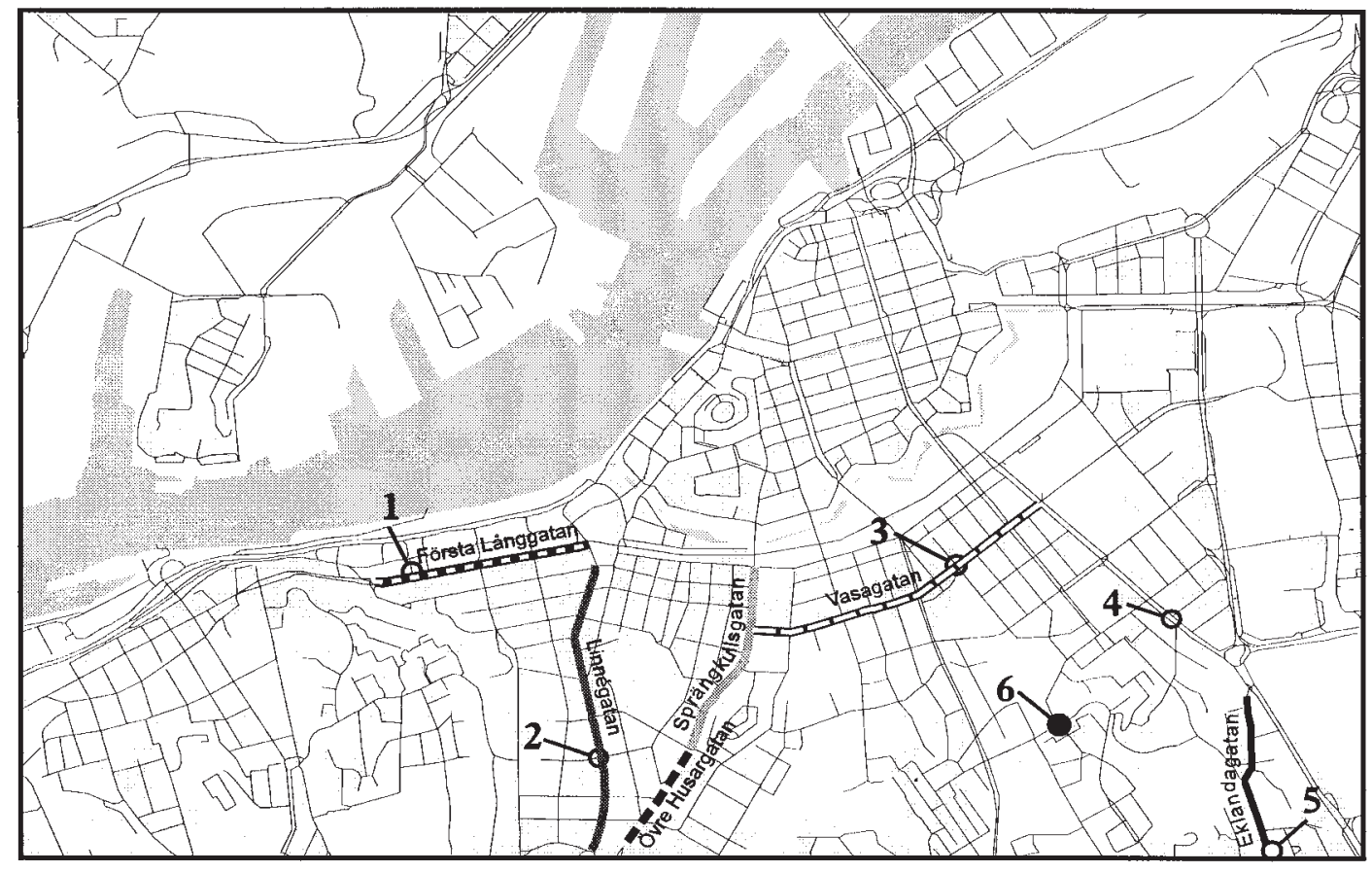

TREATED STRETCHES

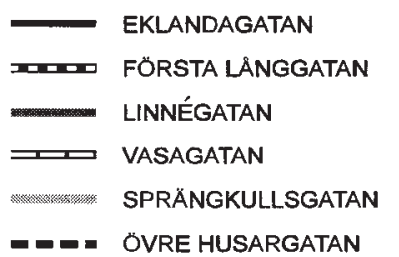

\section{FIELD STUDIES AT}

1 FÖRSTA LÅNGGATAN - SÄNKVERKSGATAN

2 LINNÉGATAN - MAJORSGATAN

3 VASAGATAN - GÖTABERGSGATAN

4 SOODRA VÄGEN - OLOF WIJKSGATAN

5 EKLANDAGATAN - UTLANDAGATAN

FIGURE 2 Treated streets (experimental area) in Gothenburg. 
types of models may also be used (2). The attribute model describes the statistical properties of the attributes on which the risk depends. In a typical situation, the attributes may vary statistically, and they are described by suitable probability distributions. The estimation of these distributions is based on the measurements. In estimation of distributions and analysis of expert judgments, a Bayesian approach is applied.

Since the parameters and attributes of the models are random variables, the risk index becomes a random variable, too. Thus, the risk index is characterized by its probability distribution. This distribution cannot be determined easily without an approximate technique. We, therefore, applied Monte-Carlo simulation.

Our original hypothesis was that a raised bicycle "path" through the intersection would improve the safety of bicyclists because of lower speeds of motor vehicles crossing their path. The primary goal of our studies has been to investigate different methods for evaluating the safety effect of this measure and compare and combine results from the different methods.

Extensive conflict studies were carried out at one junction using the Swedish Traffic Conflicts Technique (3).

As a prior function describing the opinions of bicyclists and experts on the effect of the measure, we chose the gamma distribution with density function:

$$
f(\theta)=\frac{\theta^{q-1} e^{-\theta \alpha}}{\Gamma(q) \alpha^{q}}
$$

where $\theta$ is the effect of the measure, $\Gamma(\cdot)$ is the gamma function, whereas $q>0$ and $\alpha>0$ are the parameters of the distribution. To estimate $q$ and $\alpha$, the moment method was applied, that is, the theoretical mean value $E[\theta]=q \cdot \alpha$ and variance $\operatorname{Var}[\theta]=q \cdot \alpha^{2}$ are assumed to be equal to the mean and variance of the sample of the interviewed experts.

We used the gamma distribution for modeling the distribution of index of effectiveness $\theta$ because it covers the range of feasible $\theta$ values $(0$ to $+\infty)$, it can reproduce most distributions with a single peak, and it is mathematically convenient.
For the approximation of the results from the quantitative expert judgment model we used the lognormal distribution:

$f(\theta)=\frac{1}{\theta \sigma \sqrt{2 \pi}} \exp \left[-\frac{(\ln (\theta)-\mu)^{2}}{2 \sigma^{2}}\right]$

in which $\mu$ and $\sigma$ are the parameters. The reason for using lognormal distribution is that it fits well with the results of the Monte-Carlo simulation. Another possibility would have been to use the empirical density based on the simulation results. For a more complete description of background, purpose, methods, and results, see Leden et al. (4).

\section{RESULTS}

\section{Effect on Bicycle Volumes and the Safety Effect of Changes in Volume}

Bicycle flows increased on one of the streets by 75 percent on one side and by 79 percent on the other side, and by almost exactly 100 percent on the second of the two streets where extensive measurements were taken before and after reconstruction. Measurements of bicycle flows on the two control sections indicate a general growth in bicycle flows of around 20 percent. The extra increase on our experimental sections would then be at least 50 percent, probably a result of the "better" layout.

An analysis of the relationship between bicycle flow and the number of reported accidents in the experimental area shows that the relative risk-when risk is defined as the number of expected (reported) accidents per passing bicyclist - decreases with increasing bicycle flow, as shown in Figure 3. (Figure 3 is based on a total of 276 bicycle accidents and the day is divided into eight 3-hour periods during which bicycle flows are assumed to be constant at a given site.) The line indicates that a 50 percent increase in the flow would reduce the relative risk by about 24 percent. However, the increase in the bicycle flow means that the total number of reported

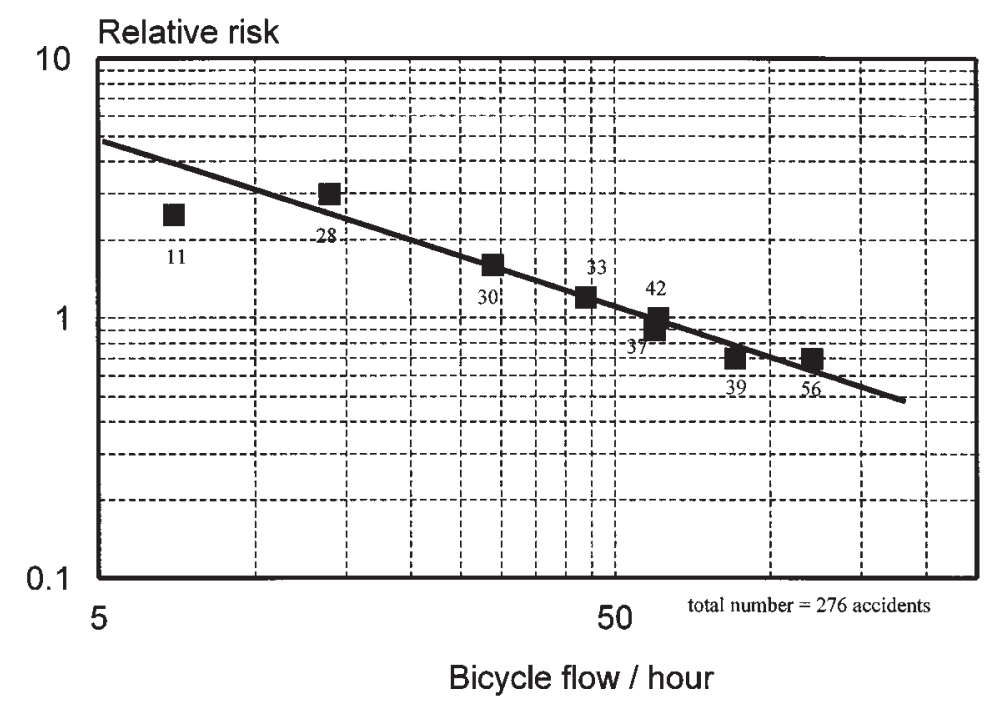

FIGURE 3 How the relative risk of a bicycle accident is affected by the bicycle flow. Logarithmic scale. (Numbers next to the data points indicate the number of bicycle accidents on which the risk ratios are based.) 
bicycle accidents would be expected to increase by about 15 percent $[1.5 \times(1-0.24)=1.14]$. If the bicycle flow is doubled, for example, from 50 to 100 bicyclists per hour, the relative risk would be reduced by 38 percent, whereas the total number of reported accidents would grow by about 25 percent $[2 \times(1-0.38)=1.24]$. It is not obvious that these results can be generalized to forecast the effect of changing bicycle flows at other locations. However, similar results have been found for changes in pedestrian flows; see, for example, Leden (5).

\section{Effect on Speeds}

The raised bicycle crossings have generally led to reduced motor vehicle speeds. The velocity of turning motor vehicles was, on average, reduced by 40 percent as a result of this intervention. The velocity of motor vehicles crossing the raised path after the intervention is, generally, around 10 to $15 \mathrm{~km} / \mathrm{h}$.

The velocity of bicyclists was measured at four intersections before, as well as after, the intervention. This velocity was reduced significantly at one intersection (where bicyclists now enter the elevated intersection on a rather steep ramp), increased by 13 percent at one (probably because they now feel more secure), and remained approximately constant at the other two. For one of these two, bicyclists were moved from the roadway to an elevated bicycle crossing. An increase in speed of around 13 percent was observed as typical for the case in which bicyclists rode on a nonelevated bicycle crossing before the intervention and on an elevated one afterward.

\section{Safety Effects According to Survey of Bicyclists}

Randomly chosen bicyclists passing through the treated intersections were asked about their assessment of safety after the reconstruction compared with before. Analysis shows that there was not a great variation in results from the four different locations included in this query. As an example, we show the results from Första LånggatanSänkverksgatan. Figure 4 shows that there is an equal chance that the index of effectiveness is above or below 0.8 ; that is, bicyclists per- ceived, on average, a 20 percent improvement at this location. The standard deviation is relatively large, 0.24 . The distribution is somewhat skewed, giving the most likely index of effectiveness to be 0.72 (where the likelihood curve is at its maximum).

\section{Safety Effects Based on Experts’ Assessments}

We developed a quantitative model based on the stated opinions of experts concerning relations between the initial speed of the motor vehicles and bicycles, respectively, and collision and injury risk. The average velocity of right-turning motor vehicles was reduced by 40 percent when a conventional bicycle crossing was raised $12 \mathrm{~cm}$ with a short ramp. The model implies that this by itself would mean a significant reduction in the number of bicycle-motor vehicle accidents. However, according to the experts, collision risk is more sensitive to changes in bicycle speeds than in car speeds, and a 13 percent increase in speed among bicyclists would increase the risk by about 40 percent. Thus, the model estimates the combined effect of decreasing vehicle speeds and increasing bicycle speeds as a 10 percent decrease in the number of bicycle-motor vehicle accidents, indicating that the positive effect of the reduced automobile velocities, unfortunately, is almost completely canceled out by the increased speeds of bicyclists (see Figure 5). Figure 5 also shows that this estimate is far from precise.

Besides agreeing on the basic relationship between the initial speed of the motor vehicle and the risk of collision, the experts also concurred with respect to the shape of the relationship between time to accident — as defined by Hydén (3) — and speed, between initial speed of motor vehicle and risk of collision, as well as between motor vehicle speed at impact and risk of injury. However, there was no agreement with respect to risk of collision versus conflicting automobile flow or risk of collision versus bicycle flow.

We also explored how the estimates are affected if injury risk is estimated instead of collision risk. As expected, the injury risk is reduced more than the collision risk when car speeds decrease. This indicates that the combined effect of decreasing car speeds and increasing bicycle speeds clearly could have a positive effect on injury risk.

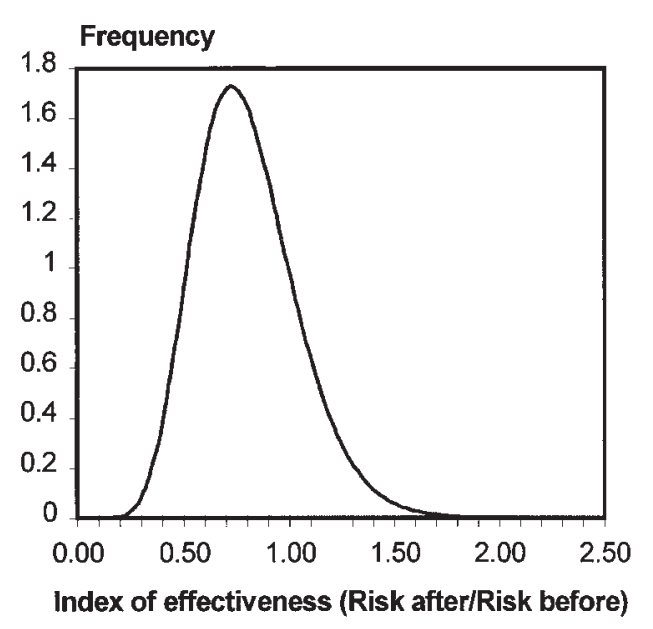

FIGURE 4 Bicyclists' prior distribution of the risk index after elevating the bicycle crossing. Estimated parameters for the gamma distribution: 11.11 and 0.072 .

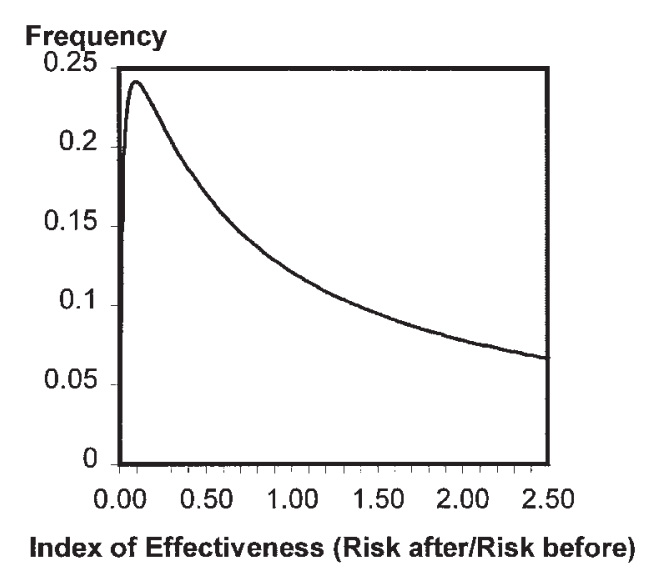

FIGURE 5 Distribution of the risk index according to the quantitative expert judgment model estimating the effect of elevating a bicycle crossing. Estimated parameters for the lognormal distribution: $\mathbf{- 0 . 1 2 3 7}$ and $\mathbf{1 . 7 4}$. 
When asked directly about the effect of raising the path $10 \mathrm{~cm}$ and paving it red, the experts estimated, on average, a 30 percent improvement in safety. Average for $\theta$ was estimated to be 0.71 with a standard deviation of 0.28 , which gives us an estimated prior distribution of the risk index according to Figure 6. It is remarkable how similar the variation in the bicyclists' and experts' estimates are (Figure 4 versus Figure 6). The effect according to the experts is, on average, slightly greater than that suggested by the bicyclists. However, it must be kept in mind that the experts were told that all other external factors, including bicycle flow volumes, were to be considered unchanged. Bicyclists may have considered changes in bicycle flow.

\section{Conflict Studies and Studies of Behavior}

A total of 315 hours of conflict studies were performed at five experimental junctions. The majority of this time ( 225 hours) focused on the T-intersection Södra vägen-Olof Wijksgatan. Before the treatment, bicyclists here rode in the roadway. After the reconstruction, they ride on an elevated bicycle crossing east of a central refuge (where they may conflict with turning vehicles exiting from the street parallel to the bicycle path). West of the refuge island (where conflicting vehicles must yield before they enter the major street), only the pedestrian crossing is elevated. Bicyclists have a smooth transition between the elevated and nonelevated sections of the crossing.

The total number of conflicts was reduced (from 39 per 100 hours of observation before reconstruction to 20 after reconstruction). However, there were six conflicts between motorists and bicyclists riding along Södra vägen before reconstruction and seven after reconstruction. (This still indicates a reduction in the number of conflicts per bicyclist since the bicycle flow increased.) Conflicts involving bicyclists riding along Södra vägen was, in the before period, only 10 percent of the total number of conflicts. The number of conflicts involving bicyclists was decreased by about 20 percent, the number of conflicts involving motorists only was reduced by about 60 percent, and the number involving pedestrians was reduced by about 80 percent. In other words, bicyclists' safety was improved the least, whereas other road users, especially pedestrians, gained much more. We speculate that an important reason for this is the reduced speeds among motorists, which were reached without compromising

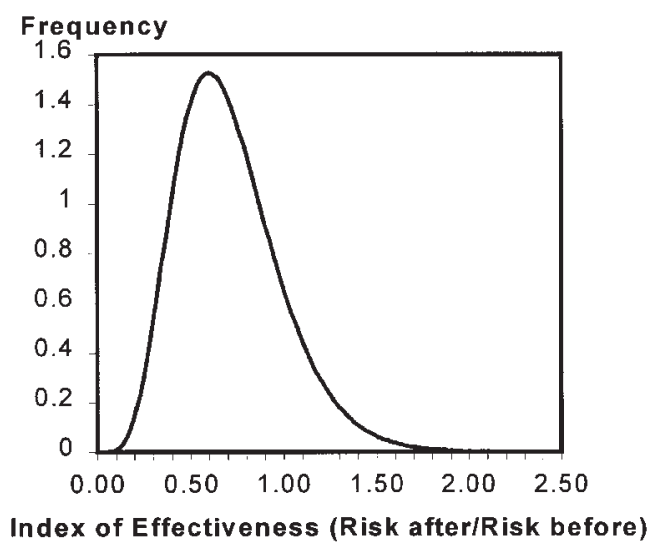

FIGURE 6 Distribution of the risk index according to the experts' estimates of the effect of elevating a bicycle crossing. Estimated parameters for the gamma distribution: 6.43 and 0.11 . the visibility of pedestrians. Also, the roadway width was reduced, giving the pedestrians a shorter distance to cross and preventing vehicles from passing a stopped vehicle at the zebra crossing.

The stopping behavior of automobile drivers at the raised crossings has been changed only marginally. Still, a high percentage of motorists block the bicycle paths while waiting for gaps in traffic on the major road.

\section{Accident Data}

The raw accident numbers from the before and after periods of the entire $18.7 \mathrm{~km}$ show that there were 160 accidents involving bicyclists in the before period $(67+$ months $)$ and 127 in the after period (varying length, but 34 months for most sections). This indicates an increase in accident frequency since the before period was longer. The accidents at the six intersections that were studied in detail are summarized in Table 1.

Note that Table 1 is included mainly to summarize reported bicycle accidents. The quotient "accident frequency after/accident frequency before" reflects not only the effect of the countermeasures but also the effect of changes in other factors, such as traffic volume, weather, vehicle fleet, driver behavior, inclination to report accidents, and so forth. In particular, it should be remembered that the number of bicyclists passing these intersections increased significantly after reconstruction. Finally, the quotient also appears to be biased due to regression-to-the-mean (4, pp. 57-59).

The number of reported accidents in the before and after periods in central Gothenburg (excluding the area of experimentation) was used for comparison purposes. Indexes of efficiency and their standard error were calculated for the reconstructed sites. Bicycle-vehicle accidents from 1,898 intersections in Gothenburg were studied to obtain information on the frequency functions. Based on a methodology developed by Hauer $(6,7)$ and Leden et al. (4), one can assess the accuracy of the estimate based on the number of reported accidents recorded at the experimental sites and the accident frequency in a population of (similar) sites. Table 2 gives an "unbiased" estimate of the number of bicycle accidents involving motor vehicles.

The index of effectiveness $(\theta)$ and its standard deviation $[\sigma(\theta)]$ are estimated to be 1.08 and 0.22 , respectively, indicating a likely increase in the number of accidents (around 8 percent). Considering that the bicycle volume grew by 50 percent more on the treated sections than citywide, an "increase" in accidents of only 8 percent compared with the comparison group should make us conclude that the countermeasures appear to be effective in enhancing the safety of bicyclists.

From a strategic perspective, one might want to reduce the number of serious injuries. Forty-eight of the 287 accidents involving bicyclists caused serious injuries to at least one of the parties, usually the bicyclist. Based on such an analysis, the priority turns out to be

1. Bicycle-automobile ( 25 out of 102 reported accidents resulted in serious injuries),

2. Bicycle-pedestrian (5 bicyclists and 11 pedestrians were seriously injured in 28 reported accidents; in total, 15 bicyclists and 22 pedestrians were injured in these accidents),

3. Single bicycle (12 out of 135 reported accidents led to serious injuries; 29 percent of these were caused by bicyclists falling while crossing streetcar tracks), and

4. Bicycle-bicycle ( 2 out of 25 reported accidents led to serious injuries). 
TABLE 1 Reported Bicycle Accidents at Treated Intersections, Jan. 1988-Sept. 1996

\begin{tabular}{cccc}
\hline Location & $\begin{array}{c}\text { Before } \\
\text { (accidents/months) }\end{array}$ & $\begin{array}{c}\text { After } \\
\text { (accidents/months) }\end{array}$ & $\begin{array}{c}\text { Accident frequency } \\
\text { after/before }\end{array}$ \\
\hline Eklandagatan - Utlandagatan & $9 / 67=0.13$ & $2 / 34=0.06$ & 0.46 \\
Linnégatan - Majorsgatan & $5 / 67=0.07$ & $0 / 34=0$ & 0 \\
Första Långgatan - Sänkverksgatan & $0 / 73=0$ & $1 / 28=0.04$ & - \\
Vasagatan - Götabergsgatan & $1 / 74=0.01$ & $0 / 27=0$ & 0 \\
Södra vägen - Olof Wijksgatan & $1 / 100=0.01$ & $0 / 4$ & $(0)$ \\
Viktor Rydbergsgatan - Läraregatan & $1 / 105=0.01$ & $0 / 0$ & $\mathrm{n} / \mathrm{a}$ \\
\hline Total & $17 / 486=0.035$ & $3 / 127=0.0236$ & 0.67 \\
\hline
\end{tabular}

There were also a few accidents involving mopeds, motorcycles, and animals (cats and dogs). It is obvious that bicycle-automobile accidents are an important part of the serious accident problem and that measures to reduce the speed of automobiles can be effective, but attention should also be focused on separating pedestrians and bicyclists along the paths and making the path surfaces even-no grates or streetcar tracks - to reduce the number of single bicycle accidents.

\section{Combined Results}

To combine the results, we used a Bayesian approach, successively adding results from the experiments to a prior distribution. Data from surveys of bicyclists and experts, as well as from the quantitative expert judgment model, were combined assuming that the before situation was a conventional bicycle crossing (e.g., Första Långgatan—Sänkverksgatan).

The starting point was the opinion of bicyclists. (Average $\theta$ was estimated to be 0.80 with a standard deviation of 0.24.) Data from the other investigations (expert survey and quantitative expert judgment model) were described by likelihood functions, and by multiplying these functions with the prior function, we received a posterior function

$f(\theta \mid x) \propto f(\theta) l(x \mid \theta)$

where

$f(\theta)=$ the prior distribution describing the uncertainty of $\theta$ before any empirical observations,

$l(x \mid \theta)=$ the likelihood function describing the probability of observations for a given value of the parameter, and

$f(\theta \mid x)=$ the posterior distribution of $\theta$, taking into account the new empirical evidence provided by the observations.

The observations $x$ are known from the new investigations, and $\theta$ is the parameter of interest, the index of effectiveness of the safety measure. [If we assume that the expected number of accidents at a site

TABLE 2 Number of Expected (Reported) Bicycle Accidents Involving Motor Vehicles Before and After Interventions at Treated Intersections

\begin{tabular}{lcc}
\hline Period & Treated intersections & Comparison \\
\hline Before & 14.2 & 266 \\
After & 9 & 155 \\
\hline Treated intersections are along Eklandagatan, \\
Första Långgatan, Linnégatan, and Vasagatan.
\end{tabular}

lacking the safety measure is $Z$, the expected number at an otherwise "identical" site with the measure is $\theta \cdot Z$. Note that when $\theta<1$, the treatment is effective and that $(100)(1-\theta)$ is the percentage reduction.]

A good introduction to Bayesian statistics is given by Lee (8). Lindley (9) gives an updated overview of Bayesian usage. Hauer (10) shows how the Bayesian approach can be used for accumulating knowledge about the effect of countermeasures on traffic safety.

For our data, the most likely combined estimate of the index of effectiveness is 0.66 ; see Figure 7. This value is based on the opinion of bicyclists and experts, as well as on the results of the quantitative expert judgment model. By combining the estimates, more information is used, and the estimate becomes more precise than if one source at a time is used. That is the advantage of using a Bayesian approach.

\section{CONCLUSIONS AND DISCUSSION}

The primary conclusions of this study, combined with results from earlier studies (11), are that

- Bicyclists have a higher risk of injury along "conventional" bicycle paths (along collector roads and arterials) where junctions are delineated by painted white rectangles than they have if sharing the roadway with automobile traffic. [A recent comprehensive analysis of "all" available studies indicates, on average, a 1 percent increase in the number of injured bicyclists as a result of constucting bicycle paths through intersections (12).]

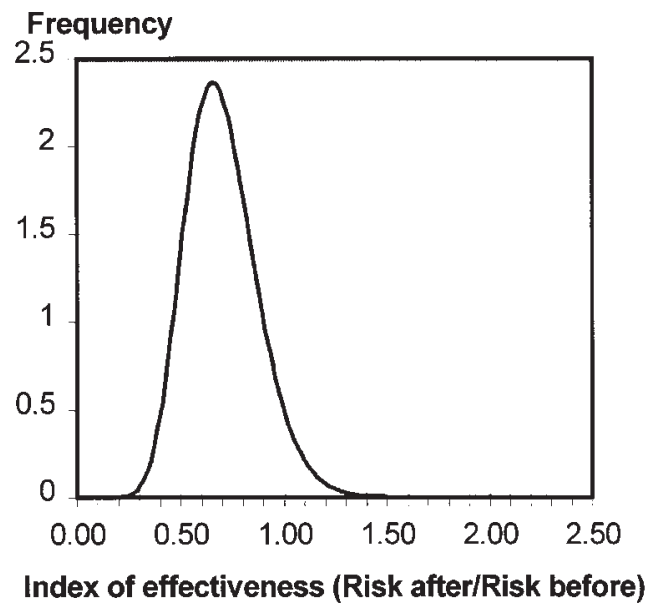

FIGURE 7 Distribution of the risk index estimating the effect of elevating an existing bicycle crossing. Combined estimates of bicyclists, experts and the quantitative expert judgment model. 
- Bicycle paths can be made reasonably safe if all bicycle crossings are raised and painted a bright color.

- Low vehicle speeds are essential in complicated environments if bicyclists' safety is to be high.

- The speed of bicyclists must also be kept relatively low in complicated environments.

Raising a bicycle crossing leads to reduced vehicle speeds, and reduced vehicle speeds lead to reduced risk. However, bicyclists' risk appears to be reduced less than what one may have hoped for. (Although a 10 to 50 percent reduction of risk is far from undesired.) One reason for this is that bicycle speeds increased somewhat. On the other hand, the reduced vehicle speeds led to the "unexpected" result of improved safety of pedestrians and motorists.

The exact magnitude of the improvement of bicyclists' safety cannot, at this point, be established. Sufficient accident data are not available. The survey of bicyclists and the direct estimate by experts indicate that safety is significantly improved. However, neither bicyclists nor experts may have taken into consideration the fact that bicyclists' speeds were increased as a result of the reconstruction. If experts were informed of that fact, they might very well have given more conservative answers. Also, bicyclists may consider their speed to be of little importance with respect to safety, whereas our survey of experts clearly shows that the "experts" hold the opposite opinion. We are bound to believe that the experts are correct in this assessment. Obviously, there are many factors other than speed that also influence the risk of injury-for example, whether the bicyclist is wearing a helmet, whether motorists yield when they should-but a bicyclist's speed can certainly influence his or her ability to take evasive action when needed.

The accuracy of our expert judgment model is not sufficiently high for drawing any firm conclusions. One reason for this is too few measurements of speeds. But, the most interesting observation from this model is not the accuracy of the estimate but the fact that the model predicts less of an improvement than direct estimates do.

Another reason that the safety of bicyclists may not be improved as much as potentially possible is that bike traffic against the allowed direction has increased somewhat as a result of the reconstruction-for example, on Södra vägen, from 4.3 percent to 6.9 percent. This is one of the drawbacks to constructing bicycle paths. The accident risk is high when riding against the allowed direction on a bike path $(13-15)$.

Another drawback is less time for interaction between bicyclists and motorists. It would be interesting to study this factor, for example, by observing when bicyclists get into the field of vision of motorists and how this reflects on the behavior of the motorists at different speeds. An areawide evaluation should also be done. Over a greater area, it is possible that the total number of accidents involving bicyclists has been reduced since bicyclists may have been attracted to the "improved" paths from less safe parallel streets, which were not included in this study.

\section{ACKNOWLEDGMENTS}

This paper is based on the information presented by Leden et al. (4). Financial support from the National Swedish Road Administration
(Lena Ericsson, Thomas Lekander, and Hans Rydgren) and from the Henry Ford Foundation made it possible to develop the Bayesian approach further to highlight its advantages.

We would also like to thank the following experts who participated in our survey: Ezra Hauer of the University of Toronto; Robert Noland of the University of California, Irvine; Alan Wachtel of Palo Alto, California; Oliver Carsten of the University of Leeds; Richard Stallard of the Bicycle Transportation Alliance, Perth, Australia; Rod Katz of the University of Sydney, Australia; Christer Hydén of the Lund Institute of Technology, Sweden; N. O. Jørgensen of Denmark's Technical University, Lyngby, Denmark; Per Nettelblad of Gatukontoret, Malmö, Sweden; Risto Kulmala of VTT, Espoo, Finland; Ralf Risser of Factum, Vienna, Austria; Richard van der Horst of TNO Institute for Perception, Soesterberg, the Netherlands; and Siem Oppe of SWOV, Leidschendam, the Netherlands.

\section{REFERENCES}

1. Mosleh, A., and G. Apostolakis. Models for the Use of Expert Opinions. In Low-Probability, High-Consequence Risk Analysis (R. A. Waller and V. T. Covello, eds.), 1984, pp. 107-124.

2. Pulkkinen, U. Statistical Models for Expert Judgement and Wear Prediction. VTT Publications 181. Technical Research Centre of Finland, Espoo, 1994.

3. Hydén C. The Development of a Method for Traffic Safety Evaluation: The Swedish Traffic Conflicts Technique. Bulletin 70. Department of Traffic Planning and Engineering, Lund Institute of Technology, Lund, Sweden, 1987.

4. Leden, L., A. Claesson, P. Gårder, P. Näsman, U. Pulkkinen, and T. Thedéen. Metodik för före-/-efterstudier. Tillämpat på cyklisters säkerhet $i$ korsningar [Methodology for Before-and-After Studies Applied to Bicyclists' Safety at Junctions]. KFB-rapport 1997:15. Stockholm, Sweden, 1997.

5. Leden, L. Pedestrian Risk Decrease with Pedestrian Flow and Increase with Vehicle Flow-A Case Study. ICTCT and Department of Traffic Planning and Engineering, Lund Institute of Technology, Lund, Sweden, 1997.

6. Hauer, E. How to Do a Before-and-After Study: Estimating the Effect of Highway and Traffic Engineering Measures on Safety. Toronto, Lecture notes, Workshop, Transport Canada, Ottawa, March 30 and 31, 1992.

7. Hauer, E. Observational Before-After Studies in Road Safety. Pergamon Press, 1997.

8. Lee, P. Bayesian Statistics: An Introduction. Oxford University Press, Oxford, U.K., 1989.

9. Lindley, D. Wald Lectures: Bayesian Statistics. Statistical Science, Vol. 5, 1990, pp. 1 ff.

10. Hauer, E. An Application of the Likelihood/Bayes Approach to the Estimation of Countermeasures' Effectiveness. Accident Analysis and Prevention, Vol. 15, 1983, pp. 287-298.

11. Gårder, P., L. Leden, and T. Thedéen. Safety Implications of Bike Paths at Signalized Intersections. Accident Analysis and Prevention, Vol. 26 No. 4, 1994, pp. 429-439.

12. Elvik, R., A. Borger Mysen, and T. Vaa. Trafikksikkerhetshåndbok. Oslo Institute of Traffic Economics (TÖI), Oslo, Norway, 1997, p. 159.

13. Linderholm, L. Signalreglerade korsningars funktion och olycksrisk för oskyddade trafikanter-Delrapport 1: Cyklister. Bulletin 55. LTH, Institutionen för trafikteknik, Lund, Sweden, 1984.

14. Wachtel, A., and D. Lewiston. Risk Factors for Bicycle-Motor Vehicle Collisions at Intersections. ITE Journal, Sept. 1994, pp. 30-35.

15. Gårder, P. Bicycle Accidents in Maine: An Analysis. In Transportation Research Record 1438, TRB, National Research Council, Washington, D.C., 1994, pp. 34-41.

Publication of this paper sponsored by Committee on Bicycling. 